\title{
Pandemia e crise ambiental: a alternativa ecossocialista
}

Pandemic and environmental crisis: an eco-socialist alternative Michael Löwy*

Resumo - O artigo relaciona a pandemia da Covid-19 aos efeitos deletérios do modo de produção capitalista em escala global e propõe a alternativa do ecossocialismo. Afirma que tanto as epidemias, quanto a crise ecológica, são resultantes deste modo de produção que transforma todos os seres e recursos naturais em mercadoria. Traz o ecossocialismo como uma proposta estratégica que busca transformar não só as relações de produção, as relações de propriedade, mas a própria estrutura das forças produtivas. Busca também a transformação do estilo, do padrão de consumo, de todo o modo de vida em torno do consumo, que é o padrão do capitalismo. O ecossocialismo não se restringe à perspectiva de uma nova civilização, mas propõe uma civilização da solidariedade entre os humanos e com a natureza.

Palavras-chave: Pandemia; crise ambiental; ecossocialismo.

Abstract - This article relates the COVID-19 pandemic to deleterious effects of the capitalist mode of production on a global scale, and proposes eco-socialism as an alternative. It affirms that epidemics, like the ecological crisis, are the result of this mode of production that transforms all beings and natural resources into merchandise. It presents eco-socialism as a strategic proposition that seeks to transform not only relations of production and relations of property, but the actual structure of productive forces. It also looks for the transformation of the style, the pattern of consumption, the whole way of life dedicated to consumption, which is the pattern of capitalism. Eco-socialism is not restricted to the perspective of a new civilization, but rather a civilization of solidarity between humans and nature.

Keywords: pandemic; environmental crisis; eco-socialism.

* Diretor de pesquisas no Centre National de la Recherche Scientifique (CNRS). E-mail: michael.lowy1@gmail.com. ORCID: https://orcid.org/0000-0001-5679-0927. 
A atual pandemia da Covid-19 é mais um exemplo das dramáticas consequências de um sistema econômico perverso e totalmente insustentável. Se conseguirmos nos livrar desta, outras epidemias aparecerão, enquanto continuar a destruição do meio ambiente, a transformação de todos os animais em mercadorias e a invasão das florestas pelo agronegócio. E quaisquer que sejam suas origens precisas em um ou outro ponto do planeta, enquanto continuar a globalização neoliberal e a movimentação incessante de mercadorias e de passageiros de um lugar para outro, elas se estenderão inevitavelmente pelo mundo inteiro. A multiplicação irracional do transporte marítimo e aéreo, resultado inevitável das políticas neoliberais de deslocalização da produção, é ao mesmo tempo uma fonte crescente de emissões de $\mathrm{CO}^{2}$ e um vetor de propagação do vírus. A crise sanitária e a crise ecológica estão intimamente associadas, são inseparáveis, e resultam da dinâmica de expansão ilimitada do capitalismo.

Não por acaso, os governos neofascistas e ecocidas são os que se recusaram a tomar medidas sérias para conter a pandemia. Qualificando a Covid-19 de "gripezinha", rejeitando as políticas de prevenção mínima indispensáveis e priorizando a continuação da atividade econômica a qualquer preço, os Bolsonaros e Trumps permitiram que o vírus se estendesse por seus países, resultando em centenas de milhares de vítimas. Sua lógica é a do social-darwinismo fascista: a sobrevivência dos mais fortes. Os fracos, doentes, idosos e vulneráveis têm mesmo é que desaparecer. Confrontado com as cifras aterradoras dos mortos, vítimas da pandemia, Jair Bolsonaro respondeu: "E daí? Vou fazer o quê?"

Estes são exatamente os mesmos governos que negam ou minimizam a mudança climática, e fazem de tudo para encorajar a oligarquia fóssil do petróleo e do carvão (Estados Unidos) e a oligarquia do agronegócio da soja e do gado (Brasil) a continuar sua obra de destruição, emitindo mais e mais $\mathrm{CO}^{2}$ na atmosfera e destruindo as últimas florestas do planeta. Sua lógica ecocida no terreno ambiental e sua necropolítica no terreno sanitário são também inseparáveis.

Também não é por acaso que Cuba, um dos poucos países que têm tentado implementar uma política econômica mais ecológica - em parte por necessidade, devido à falta de petróleo -, é aquele que consegue melhor enfrentar a crise do coronavírus, graças a enérgicas medidas de prevenção e a um sistema de saúde pública e medicina social altamente desenvolvido.

As epidemias e a crise ecológicas resultam ambas de um sistema que transforma tudo - a terra, a água, o ar que respiramos, os animais, os seres humanos - em mercadoria, e que não conhece outro critério a não ser a expansão dos negócios e a acumulaçâo dos lucros.

Os cientistas preveniram: se continuar o business as usual do capitalismo, no futuro próximo enfrentaremos desastres sem precedente na história humana. Há alguns anos atrás, quando se falava dos perigos de ca- 
tástrofes ecológicas, os autores se referiam ao futuro dos nossos netos ou bisnetos, a algo que estaria num futuro logínquo, dentro de cem anos. Agora, porém, o processo de devastação da natureza, de deterioração do meio ambiente e de mudança climática se acelerou a tal ponto que não estamos mais discutindo um futuro a longo prazo. Estamos falando de processos que já estão em curso - a catástrofe já começou, esta é a realidade. E realmente estamos numa corrida contra o tempo para tentar impedir, brecar, conter esse processo desastroso.

Quais são os sinais que mostram o caráter cada vez mais destrutivo do processo de acumulação capitalista em escala global? Epidemias como a da Covid-19 são um destes sinais. Mas o mais perigoso é o processo de mudança climática, um processo que resulta do $\mathrm{CO}^{2}$ e de outros gases emitidos pela indústria, pelo agronegócio e pelo sistema de transporte existentes nas sociedades capitalistas modernas, gerando o efeito estufa. Esta mudança, na realidade, já começou. Segundo os cientistas, se a temperatura do planeta aumentar em mais de 1,5 graus em relação à época pré-industrial, o processo de aquecimento global se tornará irreversível e incontrolável, podendo subir em 5, 6, 7 ou mais graus. Isto terá como resultado não só o aumento insuportável da temperatura em todo planeta, mas a desertificação de regiões inteiras de vários continentes, a elevação do nível do mar, o desaparecimento de cidades marítimas - Veneza, Amsterdam, Hong-Kong, Rio de Janeiro - debaixo do oceano. Uma série de catástrofes que se colocam no horizonte dentro de - não se sabe - vinte, trinta, quarenta anos, isto é, no futuro próximo. A partir de que momento a sobrevivência humana estará em perigo? Ninguém pode responder a esta pergunta. O que podemos ter certeza é de que não há um outro planeta à nossa disposição...

Tudo isso não resulta do excesso de população, como dizem alguns, nem da tecnologia em si, abstratamente, ou tampouco da má vontade do gênero humano. Trata-se de algo muito concreto: as consequências do processo de acumulação do capital, em particular na sua forma atual, da globalização neoliberal sob a hegemonia do império norte-americano. Este é o elemento essencial, motor desse processo e dessa lógica destrutiva que corresponde à necessidade de expansão ilimitada - aquilo que Hegel chamava de "má infinitude" -, um processo infinito de acumulação de mercadorias, acumulação do capital, acumulação do lucro, que é inerente à lógica do capital.

Não se trata da "má vontade" de tal ou qual multinacional ou governo, mas da lógica intrinsecamente perversa do sistema capitalista, baseado na concorrência impiedosa, nas exigências de rentabilidade, na corrida atrás do lucro rápido; uma lógica que é necessariamente destruidora do meio ambiente e responsável pela catastrófica mudança do clima.

A questão da ecologia, do meio ambiente, é a questão do capitalismo; para parafrasear uma observação do filósofo da Escola de 


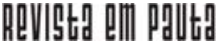

\} PANDEMIA E CRISE AMBIENTAL - LÖWY, M. \}

DOI: 10.12957/REP.2021.60290

Frankfurt, Max Horkheimer (1939) - "se você não quiser falar do capitalismo, é melhor não falar do fascismo" -, eu diria também: se você não quer falar do capitalismo, não adianta falar do meio ambiente, porque a questão da destruição, da devastação, do envenenamento ambiental é produto do processo de acumulação do capital. Logo, a questão que se coloca é a de uma alternativa, mas de uma alternativa que seja radical.

As tentativas de soluções "moderadas" se revelam completamente incapazes de enfrentar esse processo catastrófico. O chamado Tratado de Kioto está muito aquém, quase infinitamente aquém do que seria o necessário, e ainda assim o governo norte-americano, principal poluidor, campeão da poluição planetária, recusa-se a assiná-lo. O Tratado de Kioto, na realidade, propõe resolver o problema das emissões de gases de estufa por meio do assim chamado "mercado dos direitos de poluir". As empresas que emitem mais $\mathrm{CO}^{2}$ vão comprar de outras, que poluem menos, direitos de emissão. Isto seria "a solução" do problema para o efeito estufa! Obviamente, as soluções que aceitam as regras do jogo capitalista, que se adaptam às regras do mercado, que aceitam a lógica de expansão infinita do capital, não são soluções, pois são incapazes de enfrentar a crise ambiental - uma crise que se transforma, devido à mudança climática, numa crise de sobrevivência da espécie humana.

A Conferência das Nações Unidas sobre a Mudança Climática, de dezembro de 2009 em Copenhagen, foi mais um exemplo clamoroso da incapacidade - ou da falta de interesse - das potências capitalistas em enfrentar o dramático desafio do aquecimento global. A montanha de Copenhagen pariu um rato, uma miserável "declaração política", sem nenhum compromisso concreto de redução das emissões com efeito estufa.

De todas estas conferências sobre o clima das Nações Unidas, a mais bem sucedida, segundo seus organizadores, foi a COP 21 de Paris, em 2015. Os governos participantes reconheceram a necessidade de não superar o limite de 1,5 graus de aquecimento, e cada um deles anunciou publicamente um compromisso de redução de emissões em seu país. Dois pequenos problemas reduzem bastante o brilho deste evento : 1) cinco anos depois, nenhum destes governos (salvo em algumas pequenas ilhas do Pacífico) cumpriu suas promessas; 2) segundo o cálculo dos cientistas do Grupo Internacional de Estudo do Clima (Giec), mesmo se todos os países cumprissem suas promessas, a temperatura acabaria subindo em 3,3 graus.

Precisamos pensar, portanto, em alternativas radicais, em alternativas que coloquem um outro horizonte histórico, mais além do capitalismo, mais além das regras de acumulação capitalista e da lógica do lucro e da mercadoria. Como uma alternativa radical é aquela que vai à raiz do problema, que é o capitalismo, essa alternativa é o ecossocialismo, uma proposta estratégica que resulta da convergência entre a reflexão ecológica e a reflexão socialista, a reflexão marxista. Existe hoje em escala 
mundial uma corrente ecossocialista: há um movimento ecossocialista internacional, que recentemente, por ocasião do Fórum Social Mundial de Belém (janeiro de 2009), publicou uma declaração sobre a mudança climática. E existe aqui, no Brasil, uma rede ecossocialista que publicou também um manifesto, há alguns anos.

Ao mesmo tempo, o ecossocialismo é uma reflexão crítica. Em primeiro lugar, crítica à ecologia não socialista, à ecologia capitalista ou reformista, que considera possível reformar o capitalismo, atingir um capitalismo mais verde, mais respeitoso ao meio ambiente. Trata-se da crítica e da busca de superação dessa ecologia reformista, limitada, que não aceita a perspectiva socialista, que não se relaciona com o processo da luta de classes, que não coloca a questão da propriedade dos meios de produção. Mas o ecossocialismo é também uma crítica ao socialismo não ecológico, por exemplo, da União Soviética, onde a perspectiva socialista se perdeu rapidamente com o processo de burocratização e o resultado foi um processo de industrialização tremendamente destruidor do meio ambiente. O envenenamento do lago de Aral e a catastrofe nuclear de Tchernobyl são apenas alguns dos exemplos do caráter ecologicamente desastroso de um processo que procurou imitar a tecnologia e a dinâmica produtivista das economias capitalistas.

Há outras experiências socialistas, porém, mais interessantes do ponto de vista ecológico, como a experiência cubana, por exemplo. $O$ desenvolvimento de uma agricultura ecológica, a reduzida circulaçâo de automóveis, a baixa intensidade do consumismo são alguns dos aspectos positivos deste modelo. Sem dúvidas estas opções têm causas objetivas - a escassez de petróleo -, mas existe uma vontade política de favorecer uma transição ecológica.

Deste modo, o ecossocialismo implica uma crítica profunda, uma crítica radical das experiências e das concepções tecnocráticas, burocráticas e não ecológicas de construção do socialismo. Isso nos exige também uma reflexão crítica sobre a herança marxista, o pensamento e a tradição marxista, sobre a questão do meio ambiente. Muitos ecologistas criticam Marx por considerá-lo um produtivista, tanto quanto os capitalistas. Tal crítica me parece completamente equivocada: ao fazer a crítica do fetichismo da mercadoria, é justamente Marx quem coloca a crítica mais radical à lógica produtivista do capitalismo, à ideia de que a produção de mais e mais mercadorias é o objetivo fundamental da economia e da sociedade. O objetivo do socialismo, explica Marx, não é produzir uma quantidade infinita de bens, mas sim reduzir a jornada de trabalho, dar ao trabalhador tempo livre para participar da vida política, estudar, jogar, amar. Portanto, Marx fornece as armas para uma crítica radical do produtivismo e, notadamente, do produtivismo capitalista. No primeiro volume de O capital, Marx (1968) explica como o capitalismo esgota não só as energias do trabalhador, mas também as próprias forças da Terra, esgotando as riquezas naturais, des- 


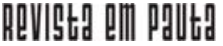

\} PANDEMIA E CRISE AMBIENTAL - LÖWY, M. \}

DOI: 10.12957/REP.2021.60290

truindo o próprio planeta. Assim, essa perspectiva, essa sensibilidade está presente nos escritos de Marx, embora não tenha sido suficientemente desenvolvida.

O problema é que a afirmação de Marx - e mais ainda, de Engels - de que o socialismo é a solução da contradição entre o desenvolvimento das forças produtivas e as relações de produção foi interpretada por muitos marxistas de forma mecânica: o crescimento das forças produtivas do capitalismo se choca com os limites que são as relações de produção burguesas - a propriedade privada dos meios de produção -, e portanto a tarefa da revolução socialista seria simplesmente destruir as relações de produção existentes, a propriedade privada, e permitir assim o livre desenvolvimento das forças produtivas.

Parece-me que essa interpretação de Marx e de Engels deve ser criticada, porque ela pressupõe que as forças produtivas sejam algo neutro; o capitalismo as teria desenvolvido até um certo ponto e não pôde ir além porque foi impedido por aquela barreira, aquele obstáculo que deve ser afastado para permitir uma expansão ilimitada. Essa visão deixa de lado o fato de que as forças produtivas existentes não são neutras: elas são capitalistas em sua dinâmica e seu funcionamento e, portanto, são destruidoras da saúde do trabalhador, bem como do meio ambiente. A própria estrutura do processo produtivo, da tecnologia e da reflexão científica a serviço dessa tecnologia e desse aparelho produtivo é inteiramente impregnada pela lógica do capitalismo e leva inevitavelmente à destruiçâo dos equilíbrios ecológicos do planeta.

O que se necessita, por conseguinte, é de uma visão muito mais radical e profunda do que seja uma revolução socialista. Trata-se de transformar não só as relações de produção, as relações de propriedade, mas a própria estrutura das forças produtivas, a estrutura do aparelho produtivo e do sistema de energia (baseado nos produtos fósseis). Esta é, na minha concepção, uma das ideias fundamentais do ecossocialismo. Há que aplicar ao aparelho produtivo a mesma lógica que Marx aplicava ao aparelho de Estado a partir da experiência da Comuna de Paris, quando ele diz o seguinte: os trabalhadores não podem apropriar-se do aparelho de Estado burguês e usá-lo a serviço do proletariado. Não é possível, porque o aparelho do Estado burguês nunca vai estar a serviço dos trabalhadores. Então, trata-se de destruir esse aparelho de Estado e criar um outro tipo de poder.

Essa lógica tem que ser aplicada também ao aparelho produtivo: ele tem que ser senão destruído, ao menos radicalmente transformado. Ele não pode ser simplesmente apropriado pelos trabalhadores, pelo proletariado, e posto a trabalhar a seu serviço, mas precisa ser estruturalmente transformado. A título de exemplo, o sistema produtivo capitalista funciona com base em fontes de energia fósseis, responsáveis pelo aquecimento global - o carvão e o petróleo -, de modo que um processo de transição ao socialismo só é possível quando houver a substituição dessas formas de energia 
pelas energias renováveis, que são a água, o vento e, sobretudo, a energia solar. Por isso, o ecossocialismo implica uma revolução do processo de produção das fontes energéticas. É impossível separar a ideia de socialismo, de uma nova sociedade, da ideia de novas fontes de energia, em particular do sol. Alguns ecossocialistas falam do comunismo solar, pois entre o calor, a energia do Sol e o socialismo e o comunismo haveria uma espécie de afinidade eletiva.

Mas não basta tampouco transformar o aparelho produtivo, é necessário transformar também o estilo, o padrão de consumo, todo o modo de vida em torno do consumo, que é o padrão do capitalismo baseado na produção massiva de objetos artificiais, inúteis e mesmo perigosos. A lista de produtos, mercadorias e atividades empresariais que são inúteis e nocivas aos indivíduos é imensa. Tomemos um exemplo evidente: a publicidade. A publicidade é um desperdício monumental de energia humana, trabalho, papel, árvores destruídas para gasto de papel, eletricidade etc., e tudo isso para convencer o consumidor de que o sabonete $X$ é melhor que o sabonete Y. Eis um exemplo evidente do desperdício capitalista. Logo, se trata de criar um novo modo de consumo e um novo modo de vida, baseado na satisfação das verdadeiras necessidades sociais, o que é algo completamente diferente das pretensas e falsas necessidades produzidas artificialmente pela publicidade capitalista.

Uma reorganizaçâo do conjunto do modo de produção e de consumo é necessária, baseada em critérios exteriores ao mercado capitalista: as necessidades reais da população e a defesa do equilíbrio ecológico. Isto significa uma economia de transição ao socialismo, na qual a própria população - e não as "leis do mercado" ou um Bureau Político autoritário decide, num processo de planificação democrática, as prioridades e os investimentos. Esta transição conduziria não só a um novo modo de produção e a uma sociedade mais igualitária, mais solidária e mais democrática, mas também a um modo de vida alternativo, uma nova civilização, ecossocialista, superando o reino do dinheiro, os hábitos de consumo artificialmente induzidos pela publicidade e a produção ao infinito de mercadorias inúteis.

Se ficarmos só nisso, porém, seremos criticados como utópicos. Os utópicos são aqueles que apresentam uma bela perspectiva de futuro e a imagem de uma outra sociedade, o que é obviamente necessário, mas não é suficiente. $O$ ecossocialismo não só é a perspectiva de uma nova civilização, uma civilização da solidariedade - no sentido profundo da palavra, solidariedade entre os humanos, mas também com a natureza -, como é também uma estratégia de luta, desde já, aqui e agora. Não podemos esperar até o dia em que o mundo se transforme, não, nós vamos começar desde já, agora, a lutar por esses objetivos. Assim, o ecossocialismo é uma estratégia de convergência das lutas sociais e ambientais, das lutas de classe e das lutas ecológicas, contra o inimigo comum que são as políticas neo- 
liberais, a Organização Mundial do Comércio (OMC), o Fundo Monetário Internacional (FMI), o imperialismo americano, o capitalismo global. Este é o inimigo comum dos dois movimentos, o movimento ambiental e o movimento social.

Não se trata de uma abstração. Há muitos exemplos, aqui mesmo no Brasil. Como um belo exemplo do que seja uma luta ecossocialista, tivemos o combate heróico de Chico Mendes, que pagou com sua vida pelo seu compromisso de luta com os oprimidos. Como essa, há muitas outras lutas. Seja no Brasil, seja em outros países da América Latina e no mundo inteiro, cada vez mais se dá essa convergência. Mas ela não ocorre espontaneamente, tem que ser organizada conscientemente pelos militantes, pelas organizações; é preciso construir uma estratégia ecossocialista, uma estratégia convergindo as lutas sociais e as lutas ecológicas.

Esta me parece ser a resposta ao desafio, a perspectiva radical de uma transformação revolucionária da sociedade para mais além do capitalismo, sabendo que o capitalismo não vai desaparecer como vítima de suas contradições, como dizem alguns supostos marxistas. Já um grande pensador marxista do começo do século XX, Walter Bejamin, dizia que, se temos uma lição a aprender, é que o capitalismo não vai morrer de morte natural, será necessário acabar com ele... Precisamos de uma perspectiva de luta contra o capitalismo, de um paradigma de civilização alternativo e de uma estratégia de convergência das lutas sociais e ambientais, desde agora plantando as sementes dessa nova sociedade, desse futuro, plantando sementes do ecossocialismo. Esta será a única garantia, não só contra futuras pandemias, mas contra uma catástrofe ecológica com consequências inimagináveis.

A alternativa ecossocialista implica, em última análise, numa transformação revolucionária da sociedade. Mas que significa revolução? Walter Benjamin (1968, p.1232) escrevia o seguinte, em 1940: "Marx disse que as revoluçôes são as locomotivas da história mundial. Talvez as coisas se apresentem de outra maneira. Pode ser que as revoluções sejam o ato pelo qual a humanidade, que viaja neste trem, puxa o freio de urgência". O que acontece hoje em dia? O trem suicida da civilização capitalista ocidental moderna, do qual somos todos passageiros, está avançando, com uma velocidade crescente, em direção a um abismo, à catástrofe ecológica, à mudança climática. Os Trumps e Bolsonaros propõem acelerar esta corrida colocando mais e mais carvão nas fornalhas. Os governos mais "razoáveis" propõem... pintar de verde a locomotiva. O que precisamos, entretanto, é puxar os freios de urgência da revolução, antes que seja tarde demais. 


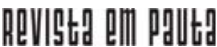

\} PANDEMIA E CRISE AMBIENTAL - LÖWY, M. \}

DOI: 10.12957/REP.2021.60290

\section{Referências}

BENJAMIN, W. Gesammelte Schriften. Vol. 1, 3. Frankfurt: Suhrkamp Verlag, 1968.

HORKHEIMER, M. Die Juden und Europa. ew York, Zeitschrifit für Sozialforschung, vol. 8, n. 1-2, 1939.

LÖWY, M. O que é o ecossocialismo? São Paulo: Ed. Cortez, 2020.

MARX, K. Le Capital, Paris, Flammarion, 1968.

DOI: 10.12957/rep.2021.60290

Recebido em 18 de dezembro de 2020.

Aprovado para publicação em 20 de janeiro de 2021.

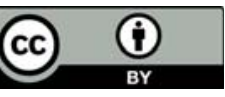

A Revista Em Pauta: Teoria Social e Realidade Contemporânea está licenciada com uma Licença Creative Commons Atribuição 4.0 Internacional. 